\title{
Güneş Enerjisi ile Reyhan Kurutma Sisteminin Tasarlanması, İmalatı, Deneysel İncelenmesi ve Alternatif Yöntemlerle Karşıllaştırılması
}

\author{
Tarkan KOCA ${ }^{1 *}$, Merve Nur POLAT ${ }^{2}$
}

${ }^{1}$ Makine Mühendisliği Bölümü, Mühendislik Fakültesi, İnönü Üniversitesi, Malatya, Türkiye

${ }^{2}$ Makine Mühendisliği Bölümü, Mühendislik Fakültesi, İnönü Üniversitesi, Malatya, Türkiye

${ }^{* 1}$ tarkan.koca@inonu.edu.tr, ${ }^{2}$ mervenuratar@gmail.com

Öz: Bu çalışmada güneş enerjisi ile reyhan kurutma sistemi tasarlanmış ve imalatı gerçekleştirilerek mor reyhan bitkisi kurutma deneyleri yapılmıştır. Deneyler üç grup şeklinde gerçekleştirilmiştir. Birinci grup deneylerde reyhanlar kurutma kabinine konmuş ve sıcaklıklar $45^{\circ} \mathrm{C}, 50^{\circ} \mathrm{C}, 55^{\circ} \mathrm{C}$ 'ye ulaştığında sabit tutulmuş ve birer saat aralıklarla kütle ölçümleri gerçekleştirilmiştir. İkinci grup deneylerde kurutma makinesinde sıcaklık $45^{\circ} \mathrm{C}, 50^{\circ} \mathrm{C}, 55^{\circ} \mathrm{C}, 60^{\circ} \mathrm{C}$ 'ye ulaştığında sabit tutularak reyhanlar kurutma makinesinin içerisine konmuş ve kuruma gerçekleştirilmiştir. Üçüncü grup deneylerde farklı başlangıç kütlesine sahip reyhanlar kurutma kabinine konularak kurumaları sağlanmıştır. Kuruma süreleri 3 ile 7 saat arasında olmuştur. Kurutma işlemlerinin tamamlanmasının ardından kurutulan ürünlerin su aktivitesi ve renk analizi deneyleri yapılmıştır. Kurutulmuş reyhanın nihai nem içeriği \%15'in altına düşürülmüştür. Su aktivite değerleri literatürde belirtilen 0,6 değerinin altında bulunmuş ve mikrobiyal büyüme açısından güvenli kabul edilebileceği sonucuna varılmıștır. Farklı sıcaklıklarda yapılan deneylerde kuruma süreleri beklendiği gibi bulunmuştur. Renk analizi deneyleri yapılmıştır. Analizler sonucunda imalatı gerçekleştirilen bu sistemin başarılı bir şekilde reyhanın kurutulmasına olanak sağladığı görülmüştür.

Anahtar kelimeler: Mor reyhan, kurutma sistemi, güneş enerjisi.

\section{Experimental Study, Design and Production of Purple Basil Drying System with Solar Power and Comparison with Alternative Methods}

\begin{abstract}
In this study, solar energy supported basil drying system was designed and manufactured while conducting purple basil plant drying experiments. The experiments were carried out in three groups. In the first group of experiments, basil having were placed in the drying chamber and when the temperatures reached $45^{\circ} \mathrm{C}, 50^{\circ} \mathrm{C}, 55^{\circ} \mathrm{C}$, the mass was measured at one hour intervals. In the second group of experiments, when the temperature reached $45^{\circ} \mathrm{C}, 50^{\circ} \mathrm{C}, 55^{\circ} \mathrm{C}, 60^{\circ} \mathrm{C}$ in the dryer, basil having were put into the dryer and dried. In the third group of experiments basil having a starting mass of different were placed in the drying cabinet and dried. Drying times were between 3 and 7 hours depending on the temperature increase. After the completion of drying process, water activity and color analysis of the dried products were performed. The final moisture content of dried basil is reduced to less than $15 \%$. Water activity values have been found below the 0,6 value specified in the literature and it has been concluded that it can be accepted as safe in terms of microbial growth. Drying times were found as expected in experiments at different temperatures. Color analysis experiments were carried out and required values were reached. As a result of the analysis, it was found that the manufactured system successfully enables the drying of basil.
\end{abstract}

Key words: Purple basil, drying system, solar energy.

\section{Giriş}

Reyhan bitkisi (Ocimum basilicum L.), Lamiacea familyasının, Ocimoideae alt familyasından Ocimum cinsinin bir türüdür [1,2]. Dünyada 65'in üzerinde türe sahip olan Ocimum bitkisinin türleri Asya, Afrika ve Orta Amerika' da doğal yayılış göstermektedir [3]. Hem taze hem de kurutulmuş olarak kullanılan reyhan bitkisi, salata, makarna, pizza, et, çorba, deniz ürünleri, tatlılar ve bazı gıda ürünlerine eklenerek farklı bir aroma katmakta ve lezzetini arttırmaktadır. Yapılan araştırmalarda reyhan bitkisinin insan sağlığı için birçok yararının olduğu tespit edilmiştir. Reyhan yapraklarının idrar söktürücü ve uyarıcı olarak kullanıldığı, öksürüğü kestiği, baş ağrısını giderdiği bilinmektedir [4]. İshal, kronik dizanteri, solunumla ilgili rahatsızlıkların, ağız ve diş hastalıklarının, mantar hastalığının tedavilerinde kullanılmaktadır [5].

\footnotetext{
* Sorumlu yazar: tarkan.koca@ inonu.edu.tr. Yazarların ORCID Numarası: ${ }^{1}$ 0000-0002-6881-4153, ${ }^{2}$ 0000-0003-4609-245X
} 
Gıdaları bozmadan uzun süre muhafaza edebilmek için kalıcı veya geçici koruma yöntemleri uygulanmaktadır. "Geçici muhafaza, gıdayı soğutarak veya soğutucuda saklayarak, gıdanın nem ve hava ile temasını keserek sağlanabilir. Kalıcı ve daha uzun süreli koruma için ise uygulanabilecek en iyi yöntem gıdaların kurutularak muhafazasını sağlamaktır" [6]. Kurutma işlemiyle gıda içeriğindeki nem seviyesinin mikroorganizmaların gelişimini engelleyecek düzeye getirilmesi amaçlanmaktadır. Kurutma teknik anlamda katının içerdiği nemin, bir gaz akımı içinde buharlaştırılarak gaza geçirilmesiyle alınmasıdır [7].

Gıdaların kurutulmasının hijyenik şartlarda gerçekleştirilmesi büyük öneme sahiptir. Tarımsal ürünlerin açık alanda yere serilerek kurutulması aflatoksin gibi zararlı etkilerin oluşmasına sebep olmaktadır. Ürün kurutucuları ile ürün kalitesinin korunarak kurutulması amaçlanmaktadır. Her alanda olduğu gibi ürünün ürün kurutucularında kurutulmasının sağlanabilmesi için enerjiye ihtiyaç vardır. Sanayi ve teknolojideki gelişmeler, enerji talebinin her geçen gün artmasına ve bu da dünyada büyük bir enerji sorununun ortaya çıkmasına sebep olmaktadır. Enerji üretiminde kullanılan, çevreye ve insanlara zarar veren petrol, kömür ve doğalgaz gibi fosil kaynaklı yakıtların yerine yenilenebilir enerji kaynaklarına yönelim artmaktadır. Yenilenebilir enerji kaynaklarından olan güneş enerjisinin kurutma işlemlerinde kullanılması oldukça önemlidir.

Reyhan tıbbi ve aromatik bir bitkidir. "Tibbi ve aromatik bitkilerin hassas yapılarından dolayı, ürüne uygun hassas kurutma yöntemlerinin seçimi ayrı bir önem arz etmektedir" [1]. Yapılan çalışmalarda reyhan bitkisinin döner tamburlu kurutucuda, doğrudan değmeli kurutucuda, etüvde, mikrodalga firınında, gölgede, güneşte, dondurarak, fırında (konvektif) kurutma, $\mathrm{CO}_{2}$ kurutma yöntemiyle, havalı kolektörler yardımıyla kurutulduğu görülmektedir. Polatcı ve Tarhan [8], reyhan bitkisini doğrudan değmeli kurutucuda, etüvde, güneşte, gölgede ve mikrodalga firında kurutmuşlardır. Korucu [9], reyhan (Ocimum Basilicum L.) bitkisini, geliştirdiği döner tamburlu kurutucuda farklı kurutma şartlarında kurutmuştur. İnan [10], reyhan bitkisini doğrudan değmeli kurutucuda farklı kurutma şartlarında kurutmuştur. Gülçimen [11], havalı güneş kolektörü, sirkülasyon fanı ve kurutma odasından oluşan deney düzeneği imal elmiş olup reyhan ve nane kurutma deneyleri yapmış ve kurutma parametreleri elde etmiştir. Cesare vd. [12], reyhan bitkisini hava ile kurutma, mikrodalga ile kurutma ve dondurarak kurutma yöntemleriyle kurutmuşlardır. Özcan vd. [13], reyhan bitkisini firında kurutma ve güneşte kurutma yöntemleriyle kurutmuştur. Akpınar [14], güneşte kurutma yöntemiyle tıbbi ve aromatik bitkilerin kurutulmasıyla ilgili deneyler yapmıştır. Diaz-Maroto vd. [15], firında kurutma, oda sıcaklığında havayla kurutma ve dondurarak kurutma yöntemleriyle reyhan (Ocimum basilicum L.) kurutmuşlardır. Demirhan ve Özbek [16], mikrodalga fırında fesleğen yapraklarını (Ocimum basillium L.) kurutmuşlardır. Baritaux vd. [17], reyhanı kurutarak saklamış, üç, altı ve yedi ay muhafaza ettikten sonra uçucu yağ analizi yapmıştır. Busic vd. [18], Ocimum basilicum L. bitkisini dondurarak, $\mathrm{CO}_{2}$ kurutma yöntemiyle ve firında kurutmuşlar. CalínSánchez vd. [19], Ocimum basilicum L. bitkisini konvektif, mikrodalga ve konvektif-mikrodalga kombine yöntemleriyle kurutmuşlardır. Hassanpouraghdam vd. [20], Ocimum basilicum L. bitkisini fırında kurutma, gölgede kurutma ve güneşte kurutma yöntemleriyle kurutmuşlardır. Tarakemeh ve Aboutalebi [21], Ocimum basilicum L. bitkisini güneşte, gölgede ve fırında kurutmuşlardır. Yousif vd. [22], Ocimum basilicum L. bitkisinin sıcak hava yardımıyla mikrodalga fırında kurutmuşlardır.

Yapılan çalışmalarda farklı güneş enerjili kurutma sistemlerinin geliştirildiği ve farklı ürünlerin kurutulmasının gerçekleştirildiği görülmektedir. Dina vd. [23], Endonezya'da yetiştirilen kakao bitkisinin çekirdeklerini kurutmak için güneş enerjisinden faydalanarak sürekli zamanlı olan kurutma makinesi tasarlamış ve imalatını gerçekleştirmişlerdir Aktaş vd. [24], güneş enerjili bir kurutucu tasarlamış, imal etmiş ve domates kurutarak analiz etmişlerdir. Akman vd. [25], güneş enerjisi destekli kurutma sisteminin tasarımını yaparak imalatını gerçekleştirmiş̧lerdir. Ceylan vd. [26], güneş enerjili havalı kollektörlü bir kurutma firınında elma kurutulmasını deneysel olarak incelemişlerdir. Romero vd. [27], dolaylı bir güneş enerjili kurutma sisteminin imalatını gerçekleştirmişlerdir. Geliştirilen bu güneş enerjili sistemler dışında farklı yöntemler kullanılarak ahlat [28], elma [29], patlıcan [30] gibi gıdaların kurutulması deneyleri de gerçekleştirilmiştir.

Yapılan çalışmalar incelendiğinde reyhan bitkisi çeşitli yöntemlerle kurutulmuştur. Yapılan bu çalışmayı diğer çalışmalardan ayıran en önemli özellik deneylerde Malatya ili mor reyhanın kullanılması ve doğrudan güneş enerjisinden faydalanılarak enerji sarfiyatı olmadan kurutmanın sağlanmasıdır. Mor reyhan coğrafi işarete sahip olup Malatya ili Arapgir ilçesinde yetiştirilmektedir. Arapgir Mor Reyhanının yaprak yapısı yumuşak olup; 5-10 cm arası uzunlukta ve 3-6 cm arası genişlikte, renk olarak koyu mor renk hâkimdir. Arapgir Mor Reyhanı yöreye özgü bir genotip olup; tamamı mor renklidir. Bu çalışmada, mor reyhan bitkisi, tasarımı ve imalatı gerçekleştirilen güneş enerjisi destekli kurutma makinesinde kurutularak; literatürde bulunan farklı kurutma yöntemleriyle kurutulan reyhan bitkisinin kuruma performanslarının ve kalite özelliklerinin karşılaştırılması amaçlanmıştır. 


\section{Materyal ve Metot}

Malatya'nın Arapgir ilçesinde yetiştiriciliği yapılan mor reyhan (Ocimum basilicum L.) örneklerinin hasadı Eylül- Ekim 2019 tarihlerinde gerçekleștirilmiştir. Toplanan reyhanlar saplarından ayrılmış ve yapraklar kurutma işlemi gerçekleştirilene kadar $+4{ }^{\circ} \mathrm{C}$ 'de muhafaza edilmiştir. Ayıklanan reyhan yapraklarının aynı boyutlarda seçilmesine özen gösterilmiştir. Taze reyhan yapraklarının başlangıç nem içeriğinin $\% 86,6 \pm 1,03$ olduğu gözlemlenmiştir.

\subsection{Reyhan kurutma deney düzeneği}

Güneş enerjisi destekli kurutma sistemi imal edilerek deneylerde kullanılmıştır. Güneş enerjisi destekli kurutucuda hedef, doğrudan güneş enerjisini kullanarak ortamın isıtılmasını sağlamak ve isıtılan ortamda bulunan reyhan yapraklarında bulunan nemin, bitkinin içyapısını bozmadan hızlı bir șekilde uzaklaştırılmasını sağlamaktır. İmal edilen güneş enerjili kurutma sisteminin genel görünümü ve şematik resmi Şekil 1 ve Şekil 2 'de verilmiştir.

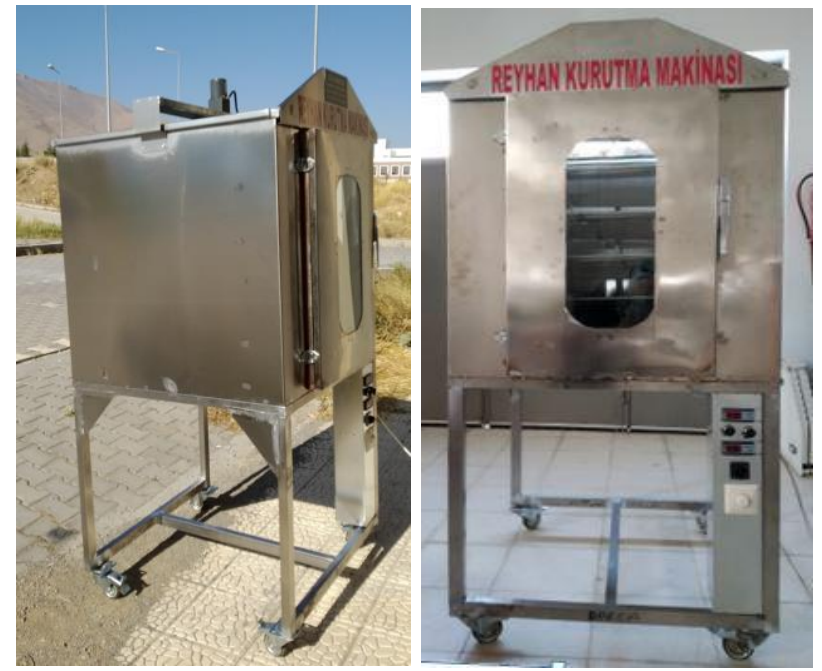

Şekil 1. Güneş enerjili kurutma sisteminin genel görünümü

Makinenin kurutma kabini 850x850x780 mm ölçülerinde metal sacdan imal edilmiştir. Kabin içerisine beş katlı döner bir raf yerleştirilmiş̧tir. Fan yardımıyla içeriye alınan havanın kurutulmak istenen reyhanların üzerine eşit dağılımını sağlamak için rafları döndürmek amacıyla redüktörlü minyatür asenkron motor kullanılmıştır. Kullanılan motorun dönme hızı 10 devir/dakika'dır. Döner raf sistemine beş adet $600 \times 400 \mathrm{~mm}$ boyutlarında delikli tepsi yerleştirilmiştir. Delikli tepsinin tercih edilmesinin sebebi reyhanların sıcak hava ile temas eden yüzey alanını artırmaktır. Sistemde hava sirkülâsyonunu sağlamak ve kabin içi sıcaklığını istenen düzeyde sabit tutmak için alüminyum gövde radyal fan kullanılmıştır. Sıcaklığın istenilen değerlerde sabit tutulmasını sağlamak için fanın otomatik kontrol yardımıyla devreye girmesi sağlanmıştır. Fan yardımıyla içeriye alınan havanın raflara homojen üflenmesini sağlamak amacıyla kurutma bölmesi içerisinde belli aralıklarla delikler açılarak bir kanal oluşturulmuştur. Kabin içi sıcaklık, dış sıcaklık ve nemi ölçmek için sıcaklık ve nem kontrol cihazı kullanılmıştır. Güneş ışınlarından maksimum düzeyde faydalanabilmek için makinenin tavan kısmı ve açma kapama kapağının bir kısmı temperli camdan imal edilmiştir.

Güneș enerjisi destekli reyhan kuruma sisteminde deneyler 21 gr ve 50 gr olmak üzere farklı kütlelerde reyhanlar kurutularak gerçekleştirilmiştir. Kütle artışının kuruma sürelerini etkileyip etkilemediği araştırılmış, $45^{\circ} \mathrm{C}, 50^{\circ} \mathrm{C}, 55^{\circ} \mathrm{C}$ ve $60^{\circ} \mathrm{C}$ 'de deneyler gerçekleştirilerek farklı sıcaklıklardaki kuruma sürelerinin kıyası yapılmıştır. Kurutulmuş reyhanların su aktivitesi, renk analizi gibi analizleri yapılmış ve literatürde bulunan diğer çalışmalarla kıyaslanmıştır. Deneyler üç grup şeklinde gerçekleştirilmiştir. Birinci grup deneylerde $21 \mathrm{gr}$ başlangıç kütlesine sahip reyhanlar kurutma kabinine konmuş ve sıcaklık istenen değere ulaştığında sabit tutularak kurumanın gerçekleşmesi sağlanmıştır. Fırın içi sıcaklığ $45^{\circ} \mathrm{C}, 50^{\circ} \mathrm{C}, 55^{\circ} \mathrm{C}$ 'ye ulaştığında sabit tutulmuş ve birer saat aralıklarla kütle ölçümleri gerçekleştirilmiştir. İkinci grup deneylerde kurutma firını güneşe konmuş ve sıcaklık $45^{\circ} \mathrm{C}, 50^{\circ} \mathrm{C}, 55^{\circ} \mathrm{C}, 60^{\circ} \mathrm{C}$ 'ye ulaştı̆̆ında sabit tutularak 21 gr başlangıç kütlesine sahip 
reyhanlar içerisine konmuş ve kuruma gerçekleştirilmiştir. Üçüncü grup deneylerde ise kurutma firını güneşe konmuş ve istenen sıcaklığa ulaşıldığında 50 gr başlangıç kütlesine sahip reyhanlar kurutma makinesine konularak kurumaları sağlanmıştır. Bu deneylerde de sıcaklıklar $45^{\circ} \mathrm{C}, 50^{\circ} \mathrm{C}, 55^{\circ} \mathrm{C}$ 'de sabit tutulmuştur. Kütle artışının kuruma zamanını etkileyip etkilemediği araştırılmıştır.

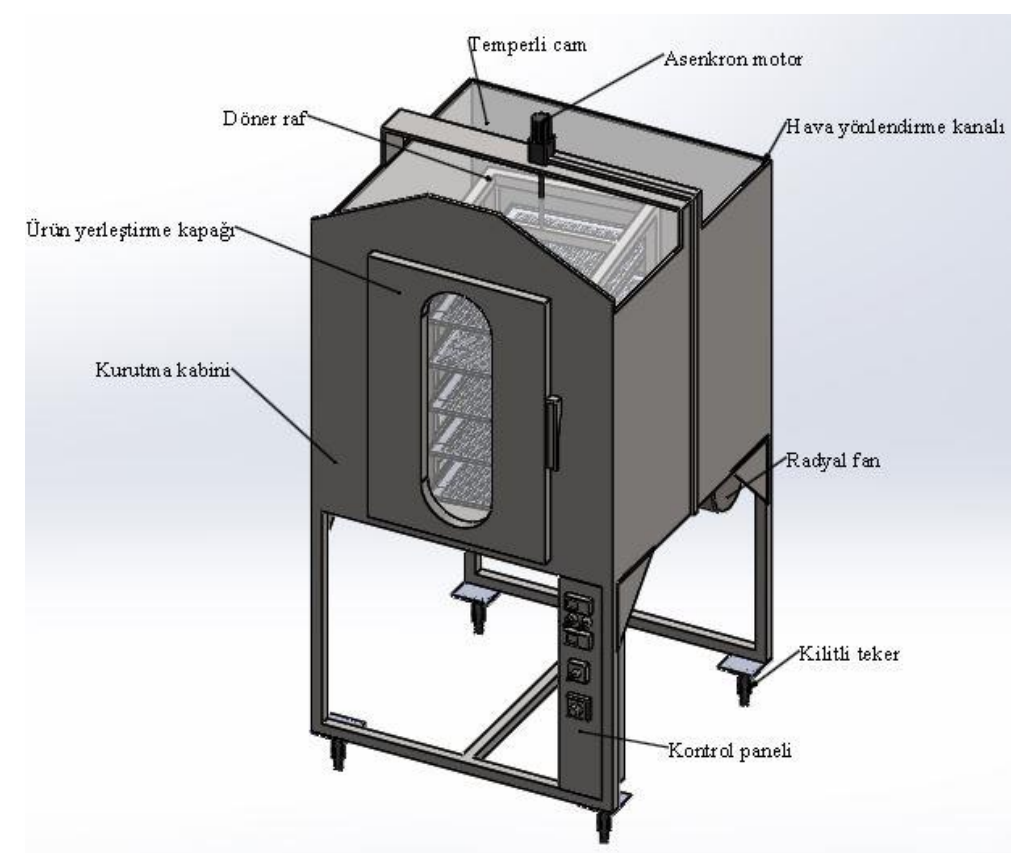

Şekil 2. Deney düzeneğinin şematik görünümü

Delikli tepsilere konularak güneş enerjili kurutma makinasında kurutulan mor reyhanların taze ve kurutulmuş görünümleri Şekil 3 'te verilmiştir.

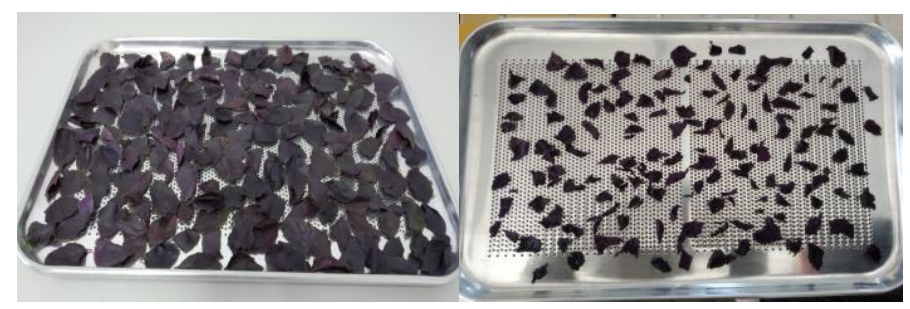

Şekil 3. Taze ve kurutulmuş mor reyhan

\subsection{Nem tayini}

Taze reyhan yapraklarının nem tayini, örneklerin $105^{\circ} \mathrm{C}$ 'de etüvde tutulması ile gerçekleştirilmiştir. Bir saatlik aralıklarla tartılan ürünlerin nem oranı aşağıda verilen Denklem 1 ve Denklem 2 kullanılarak hesaplanmıştır. Nem oranlarını belirlemek için hassas terazi kullanılmıştır. Yaş baza ve kuru baza göre nem içeriklerinin hesaplanması için aşağıdaki eşitlikler kullanılmıştır. Burada $N_{y b}$ yaş baza göre nem içeriği, $M_{s}$ sıvı kütlesi, $M_{k}$ kuru kütlesi olarak gösterilmektedir.

$\%$ yaş baza göre nem içeriği: $\% N_{y b}=\frac{M_{S}}{M_{S}+M_{k}} \times 100$

$\%$ kuru baza göre nem içeriği: $\% N_{k b}=\frac{M_{S}}{M_{k}} \times 100$ 


\subsection{Su aktivitesi tayini}

Su aktivitesi, "gidadaki suyun buhar basıncının aynı sıcaklıktaki saf suyun buhar basıncına oranıdı"” [31] şeklinde ifade edilebilir. Su aktivitesi, gıdaların muhafazasında göz önünde bulundurulan bir değerdir. 0,6'nın altındaki su aktivitesi değerine sahip gıdalar mikrop ürememesi açısından güvenli kabul edilmektedir [32]. Reyhan tozlarının su aktivitesi değerleri \pm 0.001 hassasiyete sahip su aktivitesi ölçüm cihazı kullanılarak belirlenmiştir. Su aktivitesi değerleri Denklem 3 kullanılarak hesaplanmıştır. $\mathrm{a}_{\mathrm{w}}$ su aktivitesi, P gıdadaki suyun buhar basıncı, $\mathrm{P}_{0}$ saf suyun buhar basıncı olarak alınmıştır.

$\mathrm{a}_{\mathrm{w}}=\frac{\mathrm{P}}{\mathrm{P}_{0}}$

\subsection{Renk analizi}

Reyhan tozlarının renk değerleri ölçümü colorimeter ölçüm cihazı kullanılarak belirlenmiştir. Renk analizi ölçümlerinde CIE L*, $a^{*}$ ve $b^{*}$ renk sistemi kullanılmıştır. " $L^{*}$ " 0 ile 100 arasında değer alabilmekte ve parlaklığı ifade etmektedir. 0 değerini siyah renkte alırken 100 değerini beyaz renkte almaktadır [33]. " $\mathrm{a}$ "” ifadesinin pozitif değer alması kırmızıllı̆̆ temsil ederken negatif değer alması yeşil rengi temsil etmektedir. Sıfir değer alması ise griliği temsil etmektedir [33]. "b*" ifadesinin pozitif değer alması sarılığı temsil ederken negatif değer alması maviliği temsil etmektedir. Sıfir kesim noktası griliği yani renksizliği temsil etmektedir [33]. "C*” (kroma değeri) renk doygunluğunu ifade etmektedir. Kroma değeri Denklem 4 kullanılarak hesaplanmaktadır.

$C^{*}($ Kroma $)=\sqrt{\left(a^{* 2}+b^{*^{2}}\right)}$

$H^{\circ}$ (Hue açısı ) değeri bir renk dairesi olarak tanımlanmakta olup Denklem 5 kullanılarak hesaplanmaktadır. Hue açısı kırmızı-mor renklerini $0^{\circ}$ ve $360^{\circ}$ açı değerlerinde, mavimsi yeşil rengi $180^{\circ}$ ve $270^{\circ}$ açı değerinde, sarı rengi ise $90^{\circ}$ açı değerinde almaktadır. Hue açısı.

$H^{\circ}=\tan ^{-1}\left(\frac{b^{*}}{a^{*}}\right)$

Toplam renk değişimi $(\Delta \mathrm{E})$, kahverengileşme indeksi (BI) değerleri Denklem 6, Denklem 7 ve Denklem 8 kullanılarak hesaplanmaktadır. Taze reyhan yapraklarına ait referans değerleri $L_{0}, a_{0}, b_{0}$ ile ifade edilmiştir.

$\Delta E=\sqrt{\left(\left(L^{*}-L_{0}\right)^{2}+\left(a^{*}-a_{0}\right)^{2}+\left(b^{*}+b_{0}\right)^{2}\right)}$

$\mathrm{BI}=\frac{100 \times(\mathrm{x}-0,31)}{0,17}$

$\mathrm{x}=\frac{\mathrm{a}^{*}+1,75 \mathrm{~L}^{*}}{\left(5,645 \mathrm{~L}^{*}+\mathrm{a}^{*}-3,012 \mathrm{~b}^{*}\right)}$

\section{5. Ölçüm belirsizliği}

Bir ölçüm sonucunda, ölçülen büyüklüklere etkisi olan değerlerin dağılımını karakterize eden bir parametrelere ya da ölçülen değerlerin büyüklüğünü etkileyen ve negatif olmayan sayısal ifadelere ölçüm belirsizliği adı verilir. Deney süresince yapılan tüm ölçümlerde okunan değerlerin doğruluğu çok önemlidir. Bunu sağlayabilmek için cihazların kalibrasyonu ile birlikte ölçüm belirsizlikleri de oldukça değerlidir. Deneyde kullanılan ölçüm cihazlarının hassasiyeti ve ölçüm belirsizlikleri Tablo 1'de bu verilmiştir. Sistemde ölçülmesi gereken büyüklük $R$, bu büyüklüğe etki eden $n$ adet bağımsız değişkenler ise $x_{1}, x_{2}, x_{3} \ldots, x_{n}$ olarak kabul edilerek Denklem 9 ile, her bir bağımsız değişkene ait hata oranları $w_{1}, w_{2}, w_{3} \ldots \ldots, w_{n}$ ve $R$ büyüklügünün hata oranı $W_{R}$ (belirsizlik) ise Denklem10 ile hesaplanabilir [34].

$$
\begin{aligned}
& R=R\left(x_{1}, x_{2}, x_{3}, \ldots \ldots . x_{n}\right) \\
& W_{R}=\left[\left(\frac{\partial R}{\partial x_{1}} w_{1}\right)^{2}+\left(\frac{\partial R}{\partial x_{2}} w_{2}\right)^{2}+\cdots \ldots \ldots+\left(\frac{\partial R}{\partial x_{n}} w_{n}\right)^{2}\right]^{1 / 2}
\end{aligned}
$$


Tablo 1. Ölçüm cihazlarının hassasiyetleri ve belirsizlikleri

\begin{tabular}{llll}
\hline Kullanılan cihaz & Teknik özellikleri & Hassasiyet & Belirsizlik \\
\hline Alüminyum gövde radyal fan & Güç (W) :90, Gerilim (V) :220, Debi $\left(\mathrm{m}^{3} / \mathrm{h}\right): 380$ & \pm 1 & $\pm 0,89$ \\
Redüktörlü asenkron motor & Güç:6 W Gerilim:220 V,Dönüş hızı: $10 \mathrm{~d} / \mathrm{d}$ & \pm 1 & 0,92 \\
Sıcaklık Ölçer & Ölçme skalası:-0 ${ }^{\circ} \mathrm{C} . . .+80,0$ Duyarlılık: $\pm 0,1^{\circ} \mathrm{C}$ & $\pm 0,1^{\circ} \mathrm{C}$ & $\pm 0,91^{\circ} \mathrm{C}$ \\
Nem kontrol cihazı & Ölçme skalası: $5 \ldots 95 \% \mathrm{RH}$, Duyarlılık: $\pm 1 \% \mathrm{RH}$ & \pm 2 & $\pm 1,01$ \\
Hassas terazi & Kapasite: $6000 \mathrm{gr}$, Hassasiyet: $10 \mathrm{mg}$ & $\pm 0,01 \mathrm{~g}$ & $\pm 0,49 \mathrm{~g}$ \\
Su aktivitesi ölçüm cihazı & Ölçüm aralı̆̆ı: $0,03-1,00 \mathrm{a}_{\mathrm{w}}$ Doğruluğu : $+/-0,005 \mathrm{a}_{\mathrm{w}}$ & $\pm 0,005$ & $\pm 0,001$ \\
Colorimeter CR-5, Ölçüm cihazı & Görüntü verileri: $\mathrm{L}^{*} \mathrm{a}^{*} \mathrm{~b}^{*} / \mathrm{L}^{*} \mathrm{C}^{*} \mathrm{~h}^{*}$ & $\pm 0,005$ & 0,001 \\
\hline
\end{tabular}

\section{Araştırma Bulguları ve Tartışma}

\subsection{Nem oranı}

Yapılan deneylerde kütle sabit değere ulaşana kadar saatte bir kütle ölçümü gerçekleştirilmiştir. Kabin içi sıcaklığın $45^{\circ} \mathrm{C}, 50^{\circ} \mathrm{C}$ ve $55^{\circ} \mathrm{C}^{\prime}$ ye ulaştığında sabit tutulduğu deneylerde nem oranı istenilen değerlere sirasıyla 7,6 ve 5 saatte ulaşmıştır. Şekil $4^{\prime}$ te de görüldüğü gibi $50^{\circ} \mathrm{C}$ ve $55^{\circ} \mathrm{C}$ ' ye ait kuruma eğrileri $45^{\circ} \mathrm{C}$ ' deki kuruma eğrisine oranla daha fazla dalgalanma sergilemiştir.

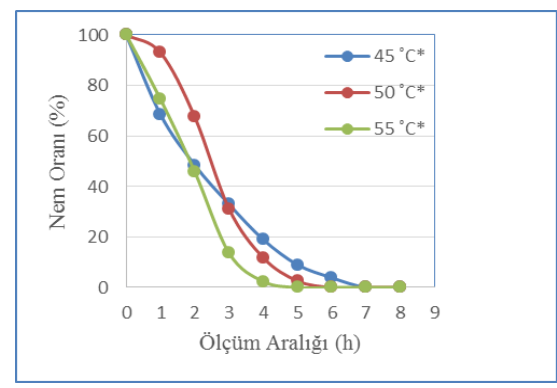

Şekil 4. Sıcaklı̆̆ın zamanla sabit değere ulaştığı deneylerin nem oranları

Kabin içi sıcaklığın $45^{\circ} \mathrm{C}, 50^{\circ} \mathrm{C}, 55^{\circ} \mathrm{C}$ ve $60^{\circ} \mathrm{C}$ ' ye ulaştığında sabit tutulup kurutulacak reyhan yapraklarının başlangıç kütleleri 21 gram ve 50 gram seçilerek raflara yerleştirildiği deneylerde nem oranlarının istenilen değerlere sırasıyla $6,5,4$ ve 3 saatte ulaştığı Şekil $5^{\prime}$ te görülmektedir. $55^{\circ} \mathrm{C}$ ve $60^{\circ} \mathrm{C}$ ye ait kuruma eğrileri benzerlik göstermektedir. Kuruma başlangıçta hızlı gerçekleşmekteyken zamanla yavaşlamıştır. Nem oranları incelendiğinde kuruma hızının zamanla azaldığı gözlemlenmektedir.

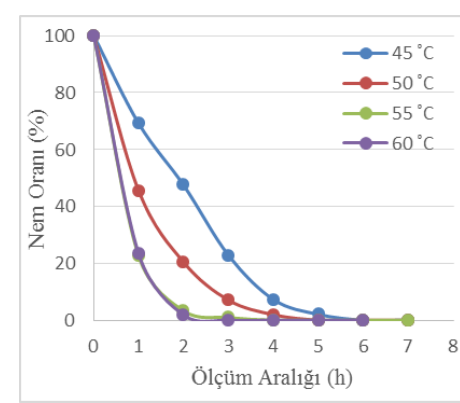

(a)

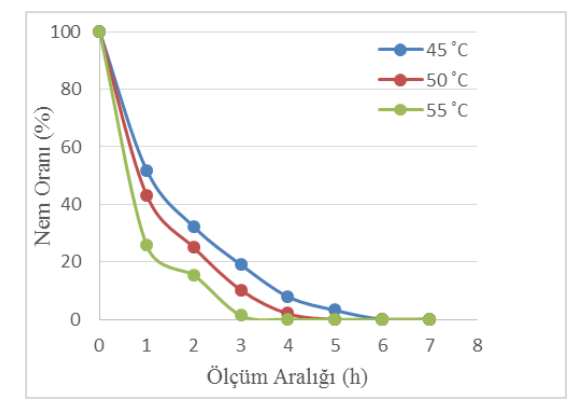

(b)

Şekil 5. Sıcaklığın başlangıçtan itibaren sabit tutulduğu deneylerin zamana bağlı nem oranları
(a) başlangıç kütlesi 21 gr
(b) başlangıç kütlesi 50 gr 


\subsection{Su aktivitesi tayini sonuçları}

0,6'nın altındaki su aktivitesi değerine sahip gıdalar mikrop ürememesi açısından güvenli kabul edilmektedir [32]. Mor reyhan bitkisinin yapraklarının farklı kurutma yöntemlerinde su aktivitesi değerlerinin 0,120 ile 0,262 aralığında olduğu gözlemlenmiştir. 0,120 ile en düşük su aktivitesi değerine $600 \mathrm{~W}$ mikrodalga gücünde kurutulan numunelerin sahip olduğu, 0,262 su aktivitesi değerine güneşte kurutulan reyhan tozlarının sahip olduğu belirlenmiştir [1]. Ocimum basilicum L. bitkisinin vakum mikrodalga kurutma yöntemi ve $48^{\circ} \mathrm{C}$ sıcak hava ile kurutma yöntemi kullanılarak kurutulduğu çalışmada su aktivitesi değerlerinin sırasıyla 0,340 ve 0,370 olarak bulunduğu gözlenmiștir [22].

Yapılan bu çalışma için Şekil 6 'daki su aktivitesi değerleri incelendiğinde en yüksek su aktivitesi değerinin $(0,454) 45^{\circ} \mathrm{C}^{\prime}$ de sıcaklı̆̆ın başlangıçta sabit tutulmadığı reyhan tozlarına, en düşük su aktivitesi değerininse $(0,405) 60^{\circ} \mathrm{C}$ sabit sicaklıkta kurutulan reyhan tozlarına ait olduğu görülmektedir.

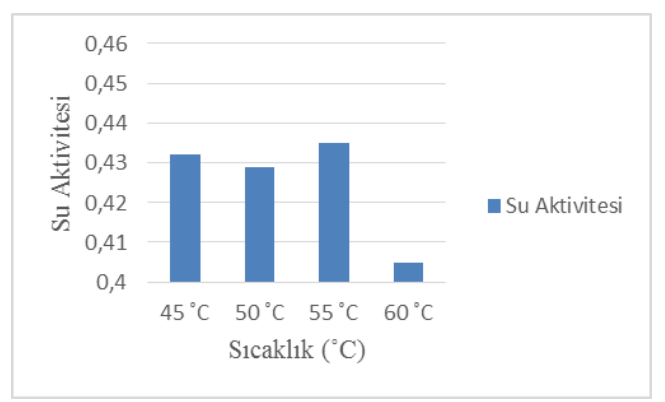

(a)

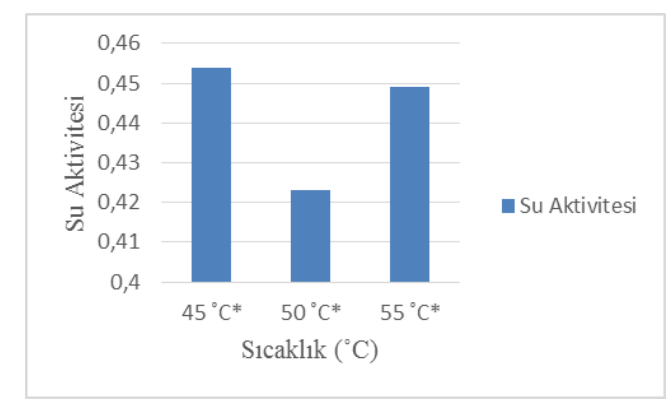

(b)

Şekil 6. Su aktivitesi tayini sonuçları (a) Sıcaklık başlangıçtan itibaren sabit (b) Sıcaklık istenilen değere ulaştığında sabit

Bahsedilen çalıșmaların su aktivitesi değerlerinin yapılan bu çalışmadaki reyhan tozlarının su aktivitesi değerlerinden düşük olduğu gözlemlenmiştir. Bu farklılık, kurutma koşulu ve kurutma yönteminin aynı olmamasından, ürünün farklı özelliklere sahip olmasından kaynaklanmaktadır.

\subsection{Renk analizi sonuçları}

Renk analizi, kurutulan ürünlerin duyusal anlamda kalitesini gösteren bir faktördür. Ürünlerin yaşken sahip oldukları rengi kurutulduğunda da koruması beklenir. Tablo 2'de literatürde bulunan reyhan kurutma çalışmalarındaki renk analiz sonuçları verilmiştir.

Tablo 2. Literatürde bulunan reyhan kurutma deneylerinde renk analiz sonuçları

\begin{tabular}{|c|c|c|c|c|c|c|c|c|}
\hline Kurutma Şekli & Yaş Rengi & $\mathbf{L}^{*}$ & $\mathbf{a}^{*}$ & $\mathbf{b}^{*}$ & $\Delta \mathbf{E}$ &, $\mathrm{C}^{*}$ & $\mathbf{H}^{\circ}$ & BI \\
\hline Mikrodalga Fırın [16] & Yeşil & $\begin{array}{l}24 \\
32\end{array}$ & $\begin{array}{l}-9 \\
-3\end{array}$ & $\begin{array}{l}7 \\
11\end{array}$ & $\begin{array}{l}5 \\
15\end{array}$ & $\begin{array}{l}8 \\
16\end{array}$ & $\begin{array}{l}110 \\
125\end{array}$ & $\begin{array}{l}30 \\
40\end{array}$ \\
\hline $\begin{array}{l}\text { Doğrudan Değmeli Kurutucu } \\
{[10]}\end{array}$ & Yeşil & $\begin{array}{l}45,94 \\
30,24\end{array}$ & $\begin{array}{l}14,04 \\
0,01\end{array}$ & $\begin{array}{l}26,37 \\
14,86\end{array}$ & $\begin{array}{l}0,00 \\
24,27\end{array}$ & $\begin{array}{l}29,89 \\
14,89\end{array}$ & $\begin{array}{l}118,06 \\
89,17\end{array}$ & $\begin{array}{l}53,4 \\
65,67\end{array}$ \\
\hline Mikrodalga Fırın [22] & Yeşil & $\begin{array}{l}35,43 \\
28,70\end{array}$ & $\begin{array}{l}6,55 \\
-1,06\end{array}$ & $\begin{array}{c}10,52 \\
9,89\end{array}$ & - & - & - & - \\
\hline Doğrudan Değmeli Kurutucu [8] & Yeşil & $\begin{array}{l}28,03 \\
48,60\end{array}$ & $\begin{array}{l}-15,82 \\
-1,44\end{array}$ & $\begin{array}{l}13,75 \\
28,39\end{array}$ & - & - & - & - \\
\hline Mikrodalga Fırın [1] & Mor & $\begin{array}{l}21,50 \\
26,80\end{array}$ & $\begin{array}{l}2,71 \\
5,49\end{array}$ & $\begin{array}{l}-0,26 \\
5,17\end{array}$ & $\begin{array}{l}0,00 \\
6,03\end{array}$ & $\begin{array}{l}2,87 \\
6,25\end{array}$ & $\begin{array}{l}19,10 \\
357,26\end{array}$ & $\begin{array}{l}14,08 \\
30,62\end{array}$ \\
\hline Döner Tamburlu Kurutucu [9] & Yeşil & $\begin{array}{l}27,33 \\
53,07\end{array}$ & $\begin{array}{l}-15,51 \\
2,57\end{array}$ & $\begin{array}{l}12,77 \\
29,02\end{array}$ & $\begin{array}{l}0 \\
28,4\end{array}$ & $\begin{array}{l}12,78 \\
31,68\end{array}$ & $\begin{array}{l}71,62 \\
89,01\end{array}$ & $\begin{array}{l}38,21 \\
73,36\end{array}$ \\
\hline
\end{tabular}

Yapılan bu çalışmada ise taze reyhan yapraklarının ve farklı sıcaklıklarda kurutulan reyhan yapraklarının $L^{*}$ değerlerinin 25,15-90,58 arasında, $a *$ değerlerinin -0,49-5,49 arasında, b* değerlerinin -0,26-0,2 arasında, $\mathrm{C}^{*}$ değerlerinin 0,52-5,49 arasında, $\mathrm{H}^{\circ}$ değerlerinin 157,86-357,26 arasında, $\Delta \mathrm{E}$ değerlerinin $0-65,70$ arasında, BI değerlerinin -0,58-14,08 arasında olduğu bulunmuştur. Renk analizi sırasında ölçülen değerler Tablo 3'te 
verilmiştir. Kurutulan reyhan tozlarının renk analizlerinde farklılıklar kurutma sıcaklıklarının değişmesinden kaynaklanmaktadır. $L^{*}$ değerleri incelendiğinde kurutulmuş ürünlerin değerleri arasında ciddi bir fark görülmektedir. Taze reyhan yapraklarına kıyasla kurutulmuş ürünlerin parlaklık değerinin arttığı tespit edilmiştir. $\mathrm{a}^{*}$ değerleri incelendiğinde taze reyhan yapraklarının kırmızılık değerinin 5,49 olduğu kurutulmuş reyhanlarınkinin ise $-0,49$ olduğu görülmektedir. Kurutulmuş ürünlerin kırmızılık değerinin negatif olması ürünlerin kurutuldukça renginin yeşile yaklaşması anlamına gelmektedir. Bunun bir diğer sebebi ise deneylerin yapıldığı mevsimde hasat edilen reyhanlarının renklerinin havaların soğumasıyla mordan yeşilimsi bir renge dönüşmesidir. $b^{*}$ değerlerine göre yaş reyhanların mavilikleri fazla olup kurutuldukça sarılıkları artmıştır.

Tablo 3. Renk analizinde ölçülen değerler

\begin{tabular}{cccc}
\hline Kurutma Sicaklıkları & $\mathbf{L}^{*}($ Parlaklık) & $\mathbf{a}^{*}($ Kırmızılık) & $\mathbf{b}^{*}($ Sarllık) \\
\hline $45^{\circ} \mathrm{C}$ & 90,55 & $-0,49$ & 0,19 \\
$50^{\circ} \mathrm{C}$ & 90,55 & $-0,49$ & 0,18 \\
$55^{\circ} \mathrm{C}$ & 90,57 & $-0,49$ & 0,19 \\
$60^{\circ} \mathrm{C}$ & 90,55 & $-0,48$ & 0,18 \\
$45^{\circ} \mathrm{C}^{*}$ & 90,58 & $-0,49$ & 0,20 \\
$50^{\circ} \mathrm{C}^{*}$ & 90,57 & $-0,49$ & 0,20 \\
$55^{\circ} \mathrm{C}^{*}$ & 90,55 & $-0,49$ & 0,17 \\
Taze Reyhan & 25,15 & 5,49 & $-0,26$ \\
\hline
\end{tabular}

Denklem 4, Denklem 5, Denklem 6, Denklem 7 ve Denklem 8 kullanılarak hesaplanan; kroma değerlerinin 0,52 ile 5,49 arasında, Hue açısının 157,86 ile 357,26 arasında olduğu, kahverengilik değerinin -0,58 ile 14,08 arasında olduğu, toplam renk değişiminin 0 ile 65,70 arasında olduğu görülmüştür. Kurutulan reyhan yapraklarının kroma değerlerinin taze reyhan yapraklarının kroma değerlerinden düşük olması, kurutulan reyhanların renginin donuklaştığını göstermektedir. Kurutulan reyhan yapraklarının Hue açısı değerleri $180^{\circ}$ ye yakın bulunurken, taze reyhan yapraklarının Hue açısı değerlerinin $360^{\circ}$ 'ye yakın olduğu bulunmuştur. Bu açı değişimi kendine özgü mor renge sahip olan reyhan yapraklarının kurutma sonrası renginin mordan siyaha yaklaşmasından kaynaklanmaktadır. Güneş enerjisi destekli reyhan kurutma sisteminde kurutulan reyhanların kahverengilik değerlerinde fark görülmekte olup bu değerlerin kurutma işlemiyle azaldığı görülmektedir.

\subsection{Kuruma Süresi}

Kurutma işlemlerinde kuruma süresi önemli bir faktördür. Tablo 4'te literatürdeki reyhan kurutma deneylerinde kuruma süreleri verilmiştir.

Tablo 4.Literatürde bulunan reyhan kurutma deneylerinde kurutma süreleri

\begin{tabular}{|c|c|c|}
\hline Kurutma Şekli & Sıcaklık- Basınç & Kurutma Süresi \\
\hline Döner tamburlu kurutucu [35]. & Sabit Sicaklık, Kademeli Sıcaklık & 39 saat, 25,5 saat \\
\hline Doğrudan değmeli kurutucu [10]. & Sabit Sicaklık, Kademeli Sicaklık & 31,5 saat, 25,5 saat \\
\hline Etüvde kurutma [8]. & $35^{\circ} \mathrm{C}, 45^{\circ} \mathrm{C}, 55^{\circ} \mathrm{C}$ & 52 saat, 50 saat, 34 saat \\
\hline Mikrodalga firın [8]. & $55^{\circ} \mathrm{C}$ & 9 dakika, 22 dakika \\
\hline Mikrodalga firın [1]. & $45^{\circ} \mathrm{C}, 50^{\circ} \mathrm{C}, 55^{\circ} \mathrm{C}$ & 8 dakika, 6 dakika, 4,5 dakika \\
\hline Vakum mikrodalga firın [22]. & $48^{\circ} \mathrm{C}$ & 1 dakika, 6 dakika, 12 dakika \\
\hline Gölgede doğal kurutma [8-15]. & Gölgede & 58 saat, 15 gün \\
\hline Güneşte doğal kurutma $[1,36]$. & Güneşte & 10 saat \\
\hline Yarı gölge doğal kurutma [13]. & $40^{\circ} \mathrm{C}, 50^{\circ} \mathrm{C}$ & 28 saat, 15 saat \\
\hline Dondurarak kurutma [18]. & $-20{ }^{\circ} \mathrm{C}, 0,005$ bar; $40^{\circ} \mathrm{C}, 80-100$ bar & 4 gün, 2, 3, 4 sat \\
\hline Havalı kolletörler yardımıyla kurutma [11]. & Farklı akış debilerinde $50^{\circ} \mathrm{C}$ & 300-480 dakika \\
\hline Firında (Konvektif) kurutma $[1,36]$. & $45^{\circ} \mathrm{C}-50^{\circ} \mathrm{C}-55^{\circ} \mathrm{C}$ & 6 saat 5 saat 4 saat \\
\hline
\end{tabular}

Reyhan kurutulurken rengi, aroması ve diğer iç özellikleri bozulmadan kurutma yapılmalıdır. Hızlı yani kısa sürede kurutmalarda bu özelliklerin bazılarının bozulduğu bilinmektedir. Bu çalışmada ise kurutma 
makinesinin içerisine kurutulacak reyhanlar yerleştirildikten sonra güneşe konulup kabin içi $45^{\circ} \mathrm{C}, 50^{\circ} \mathrm{C}$ ve $55^{\circ} \mathrm{C}$ değerlerine geldiğinde sıcaklıkların sabit tutularak kurumanın sağlandığı deneylerde bitkinin 7, 6 ve 5 saatte kuruduğu tespit edilmiştir. Kabin içi sıcaklığ $145^{\circ} \mathrm{C}, 50^{\circ} \mathrm{C}, 55^{\circ} \mathrm{C}$ ve $60^{\circ} \mathrm{C}$ değerlerine ulaştıktan sonra reyhanların makine içerisine konularak kurutulması sağlanmış ve kuruma sürelerinin sırasıly 6,5 , 4 ve 3 saat olduğu görülmüştür. Sıcaklığın başlangıçta sabit tutulup yaş mor reyhanın kütlesinin artırıldığı deneylerde ise $45^{\circ} \mathrm{C}, 50^{\circ} \mathrm{C}$ ve $55^{\circ} \mathrm{C}$ ' de kurumanın sırasıyla 6,5 ve 4 saatte gerçekleştiği belirlenmiştir. İmalatı gerçekleştirilen kurutma sisteminde sıcaklığın artırılmasıyla kuruma sürelerinde önemli ölçüde düşüş olduğu görülmektedir. Yapılan deneyler sonucunda yaş mor reyhan kütlesinin artışının kuruma süresinde değişikliğe neden olmadı̆̆ görülmüştür.

\section{Sonuçlar}

Yapılan bu çalışmada, mor reyhan bitkisinin kurutulmasını sağlamak üzere güneş enerjisi destekli reyhan kurutma sistemi tasarlanmış ve imalatı gerçekleştirilmiştir. İmal edilen bu sistemde reyhan yapraklarının başarılı bir şekilde kurutulması sağlanmıştır. Fosil yakıt kullanılan birçok kurutma sistemi olmasına rağmen, yenilenebilir enerji kaynaklarının kullanılacağı yeni bir sistemin oluşturulmaya çalışılmasının amacı, fosil yakıtlarının kullanımının azaltılmasına bir katkıda bulunmaktır. Bu sistemin tasarlanması ve imalatının yapılmasının amacı elektrik enerjisiyle havayı 1sıtma prensibine dayanan firında (konvektif) kurutma yönteminin yerine, yenilenebilir enerji olan güneş enerjisiyle havanın ısıtılarak ürünlerin kurutulmasının sağlanmasıdır. Kurutulmuş gıdaların raf ömrünü etkileyen faktörler arasında içerdikleri nem miktarı bulunmaktadır. Tıbbi ve aromatik bitkilerin sahip oldukları \%70 - 85 yüksek nem içeriğinden dolayı, raf ömrünün uzun olmasını sağlayabilmek için \%10-15 son nem oranına düşürülmeleri gerekmekte olup, yapılan bu çalışmada kurutulmuş reyhanların son nem içerikleri \%15'in altına düşürülmüş ve başarılı bir kurutma sağlanmıştır. Su aktivitesi 0,6'nın altında olan gıdalar mikrop ürememesi açısından güvenli kabul edilmektedir [32]. Bu çalışmada ise en yüksek su aktivitesi değeri farklı sicaklıklarda yapılan deneylerde 0,454- 0,405 arasında bulunmuştur. Su aktivitesi değerleri, literatürde belirtilen 0,6 değerinin altında bulunduğu için mikrop ürememesi açısından güvenli kabul edilebilir ve başarılı bir kurutma sağlanmıştır denebilir. Kurutma sürelerinde oldukça iyi sonuçlara ulaşılmıştır. İmalatı gerçekleştirilen kurutma sisteminde sıcaklığın artırılmasıyla kuruma sürelerinde önemli ölçüde düşüş olduğu gözlemlenmektedir. Yapılan deneyler sonucunda yaş mor reyhanın kütle artışının kuruma süresinde değişikliğe neden olmadığı görülmüştür. Bulunan kuruma sürelerinin mor reyhan yapraklarının firında kurutulmasıyla gerçekleştirilen deneylerle yakın olduğu görülmüştür. Güneş enerjisi destekli kurutma sisteminin başarılı bir kurutma sağladığı sonucu çıkarılmıştır.

İmal edilen reyhan kurutma sisteminde reyhan bitkisi kurutularak nem tayini, su aktivitesi tayini, renk analizi gibi analizler gerçekleştirilmiş olup sistemin başarılı bir şekilde reyhanın kurutulmasına olanak sağladığı görülmüştür.

\section{Teşekkür}

FYL-2019-1500 kodlu projeye vermiş oldukları desteklerinden dolayı İnönü Üniversitesi Bilimsel Araştırma Projeleri Koordinasyon Birimi’ne teşekkür ederiz.

\section{Kaynaklar}

[1] Altay K, Farklı yöntemlerle kurutulan Arapgir mor reyhanının (Ocimum basilicum) kuruma davranışlarının incelenmesi ve kuru ürünün bazı kalite özelliklerinin belirlenmesi. Doktora Tezi, Ege Üniversitesi, Fen Bilimleri Enstitüsü, İzmir, 2019.

[2] Aslan Öz MN, Balıkesir yöresinde doğal olarak yetişen biberiye ve fesleğen bitkilerine ait uçucu yağların antioksidan ve antimikotik özelliklerinin belirlenmesi. Yüksek Lisans Tezi, Namık Kemal Üniversitesi, Fen Bilimleri Enstitüsü, Tekirdağ, 2017.

[3] Ermişler A, Altın otu (elıchrysum arenarıum) ve fesleğen (ocimum basilicum) bitkilerinin sinek kovucu (repellent) özelliklerinin karşı1laştırılması. Yüksek Lisans Tezi, Selçuk Üniversitesi, Fen Bilimleri Enstitüsü, Konya, Türkiye, 2017.

[4] Kulan E.G, Eskişehir koşullarında yetiştirilen reyhan (ocimum basilicum 1.) bitkisinin bazı bitkisel özelliklerin ve diurnal varyabilitesinin belirlenmesi. Yüksek Lisans Tezi, Osmangazi Üniversitesi, Fen Bilimleri Enstitüsü, Eskişehir, 2013.

[5] Günay E, Telci İ, Isparta Ekolojik Koşullarında Bazı Reyhan (Ocimum basilicum L.) Genotiplerinin Verim ve Kalite Özelliklerinin Belirlenmesi Süleyman Demirel Üniversitesi Ziraat Fakültesi Dergisi 2017; 12 (2): 100-109. 
[6] Koca T, Polat MN, Reyhan kurutma yöntemleri ve karş1laştırma. International Conference On Engineering \& Natural Sciences-4 (ISPEC); 2019; Ankara, Türkiye; pp. 106-112.

[7] Ratti C, Hot-air and frezee-drying of high value foods: A Review, Journal of Food Engineering 2001; 49 (4): 311 -319.

[8] Polatc1 H, Tarhan S, Farklı kurutma yöntemlerinin reyhan (Ocimum basilicum) bitkisinin kuruma süresine ve kalitesine etkisi. Tokat Gaziosmanpaşa Üniversitesi Ziraat Fakültesi Dergisi 2009; 26 (1): 61-70.

[9] Korucu B, Yeni tip döner tamburlu kurutucunun geliştirilmesi ve reyhan (Ocimum basilicum 1.) bitkisi kurutma performansının belirlenmesi. Yüksek Lisans Tezi, Gaziosmanpaşa Üniversitesi, Fen Bilimleri Enstitüsü, Tokat, 2009.

[10] İnan E, Yeni tip doğrudan değmeli kurutucunun geliştirilmesi ve reyhan ( Ocimum basilicum 1.) bitkisini kurutma performansının belirlenmesi. Yüksek Lisans Tezi, Gaziosmanpaşa Üniversitesi, Fen Bilimleri Enstitüsü, Tokat, 2010.

[11] Gülçimen F, Yeni tasarlanan havalı kollektörler yardımı ile reyhan ve nane kurutulması. Doktora Tezi, Fırat Üniversitesi, Fen Bilimleri Enstitüsü, Elazı̆̆, 2008.

[12] Cesare LF, Forni E, Viscardi D, Nani RC, Changes in the chemical composition of basil caused by different drying procedures, Cesare, Journal of Agricultural and Food Chemistry 2003; 51 (12): 3575-3581.

[13] Özcan M, Arslan D, Ünver A, Effect of drying methods on the mineral content of basil (Ocimum basilicum L.), Journal of Food Engineering 2005; 69 (3): 375-379.

[14] Kavak AE, Mathematical modelling of thin layer drying process under open sun of some aromatic plants. Journal of Food Engineering 2006; 77 (4): 864-870.

[15] Diaz-Maroto MC, Sánchez Palomo E, Castro L, Viñas G, Pérez-Coello MS, Changes produced in the aroma compounds and structural integrity of basil (Ocimum basilicum L.) during drying. Journal of the Science of Food and Agriculture 2004; 84 (15); 2070-2076.

[16] Demirhan E, Özbek B, Microwave-drying characteristics of basil, Journal of Food Processing and Preservation 2010; 34 (3): 476-494.

[17] Baritaux O, Richard H, Touche J, Derbesy M, Effects of drying and storage of herbs and spices on the essential oil. Part I. Basil, ocimum basilicum 1992; 7 (5): 267-271.

[18] Bušić A, Vojvodić A, Komes D, Akkermans C, Belščak-Cvitanović A, Stolk M, Hofland G, Comparative evaluation of $\mathrm{CO}_{2}$ drying as an alternative drying technique of basil (Ocimum basilicum L.) - The effect on bioactive and sensory properties. Food Research International, 2014; 64 (1): 34-42.

[19] Calín-Sánchez A, Lech K, Szumny A, Figiel A, Carbonell-Barrachina A.A., Volatile composition of sweet basil essential oil (Ocimum basilicum L.) as affected by drying method. Food Research International 2012; 48 (1): 217-225.

[20] Hassanpouraghdam MB, Hassani A, Vojodi Mehrabani L, Farsad N, Drying methods affects essential oil content and composition of basil (Ocimum basilicum L.). Hassanpouraghdam Journal of Esserntial Oil Bearing Plants 2010; 13 (6): 759-766.

[21] Tarakemeh A, Aboutalebi A, Effect of drying method on the essential oil quantity of basil (Ocimum basilicum L.), Journal of Essential Oil Bearing Plants, 2012; 15 (3): 503- 505.

[22] Yousif AN, Scaman CH, Durance TD, Girard B, Flavor volatiles and physical properties of vacuum-microwave- and air-dried sweet basil (Ocimum basilicum L.). Journal of Agricultural and Food Chemistry 1999; 47 (11): 4777-4781.

[23] Dina S.F, Ambarita H, Napitupulu FH, Kawai H, Study on effectiveness of continuous solar dryer integrated with desiccant thermal storage for drying cocoa beans. Case Studies in Thermal Engineering 2015; 5 (1): 32-40.

[24] Aktaş M, Şevik S, Doğan H, Öztürk M, Fotovoltavik ve termal güneş enerjili sürekli bir kurutucuda domates kurutulmas1. Tarım Bilimleri Dergisi 2012; 18: 287-298.

[25] Akman H, Çerçi KN, Hürdoğan E, Büyükalaca O, Güneş enerjisi destekli bir kurutma sisteminin tasarımı, imalatı ve ilk ölçüm sonuçlarının değerlendirilmesi. Osmaniye Korkut Ata Üni. Fen Bilimleri Enstitüsü Dergisi 2018; 1 (1), 1-9.

[26] Ceylan İ, Aktaş M, Doğan H, Güneş enerjili kurutma firınında elma kurutulması. Politeknik Dergisi 2006; 9 (6): 289 294.

[27] Romero VM, Cerezo E, Garcia MI, Sanchez MH, Simulation and validation of vanilla drying process in an indirect solar dryer prototype using CFD Fluent program. Energy Procedia 2014; 57 (1): 1651-1658.

[28] Türk Tİ, Çelebi RS, Toğrul H, Farklı ön işlem uygulanan Ahlatın kuruma ve büzülme davranışının modellenmesi. Journal of the Faculty of Engineering and Architecture of Gazi University 2018; 33 (4): 1231-1245.

[29] Yoğurtçu H, Yanıt yüzey metodu kullanarak mikrodalga ile elma kurutmanın optimizasyonu. Ournal of the Faculty of Engineering and Architecture of Gazi University 2019; 34 (3): 1365-1376.

[30] Doymaz I, Aktaş C, Patlican dilimlerinin kurutma ve rehidrasyon karakteristiklerinin belirlenmesi. Journal of the Faculty of Engineering and Architecture of Gazi University 2018; 33 (3): 833-841.

[31] Anonim. Gıdaların fiziksel özellikleri, https://acikders.ankara.edu.tr/pluginfile.php/15137/mod_resource/content/0/DERS-12.pdf. Erişim tarihi Kasım 11, 2009.

[32] Quek SY, Chok NK, Swedlund P, The physicochemical properties of spray-dried watermelon powders. Chemical Engineering and Processing 2007; 46 (5): 386-392.

[33] McGuire RG, Reporting of objective color measurements, hortscience 1992;27(12): 1254-1255.

[34] Kline SJ, McClintock FA, Describing uncertainties in single sample experiments. Mech Eng 1953; 75 (1): 3-8.

[35] Polatc1 H, Farklı kurutma yöntemlerinin reyhan (Ocimum basilicum) bitkisinin kuruma süresine ve kalitesine etkisi. Yüksek Lisans Tezi, Gazi Osmanpaşa Üniversitesi, Fen Bilimleri Enstitüsü, Tokat, Türkiye, 2008.

[36] Altay K, Hayaloğlu AA, Dirim SN. Determination of the drying kinetics and energy efficiency of purple. Heat and Mass Transfer 2019; 55(8): 2173-2184. 